\title{
Kewirausahaan ICE CREAM FRUITY
}

\author{
Abbie L. Tozer, Vighel Listra
}

\section{BAB I PENDAHULUAN}

\section{Latar Belakang}

Makanan penutup yang lezat sangatlah diminati oleh banyak orang, tidak ada orang yang menolak makanan yang sesuai dengan selera dan lezat. Makanan penutup yang selalu dianggap lezat biasanya dilihat dari luarnya terlebih dahulu atau dapat dikatakan pandangan pertama, karena dalam makanan sangat menentukan pandangan pertama dalam melihat makanan. Karena makanan penutup yang terlihat sangat lezat akan menambah citra tersendiri untuk makanan tersebut. Makanan yang memiliki citra tersendiri juga terlihat dari penampilan yang menarik dipandang oleh orang-orang yang melihatnya. Apa lagi jika rasa dari makanan tersebut memang sangatlah lezat dan berbeda dari makanan yang sejenisnya. Itu akan menambahkan citra yang tinggi dari makanan tersebut, dan menjadikan makanan itu akan selalu dipikirkan oleh orang-orang yang menyukai makanan tersebut. Makan dengan makanan penutup yang lezat adalah cara makan yang sangat disukai banyak orang. Makanan penutup juga dapat disebut sebagai “desert” dalam pennyebutan bahasa Inggris.

Namun desert yang lezat selalu dibayang-bayangi dengan bahan yang tidak sehat, seperti halnya cheesecake, cream brulee, dan makanan penutup yang biasanya manis. Belum lagi harga desert yang tinggi yang menjadikan makanan itu tidak lezat secara psikis, walaupun makanan tersebut sangat lezat namun saat memakan sangatlah menggangu psikis karena harga yang sangat tinggi. Selalu dibayangi dengan makanan tidak sehat serta memiliki harga yang relatif tinggi membuat makanan yang lezat dari penampilan dan rasanya, menjadi jarang dirasakan oleh orang-orang karena ketidakmampuan membelinya.

Dalam proposal ini kami akan menyampaikan sebuah makanan yang sehat namun juga lezat dari penampilan maupun rasa yang sangat bercitra unik. Makanan sehat memang sangatlah diminati banyak orang, karena yang paling utama sehat dan tidak bosan untuk memakannya. Dalam produk ini kami memberikan makanan yang sudah tidak lazim bagi makanan rumahan di Indonesia. Dengan bahan pokok buah dan tambahan-tambahan yang lainnya menjadikan buah yang biasanya dalam makanan penutup rumahan ala ibu-ibu 
Indonesia sangat biasa terlihat, karena tidak diola atau hanya dibiarkan secara utuh, dan dengan produk kami ini akan menjadikan makanan penutup rumahan menjadi rasa dan tekstur yang berbeda dari biasanya. Makanan penutup yang terlihat mewah dan tidak hanya mewah rasa dan penampilan yang menggoda, serta sehat adalah makanan yang diminati banyak orang, dan yang paling utama tidak membuat keuangan akan jatuh, atau tidak mahal seperti makanan yang sangat lezat pada umumnya. Jadi dalam produk ini kami mempromosikan Ice Cream Fruity yang lezat, sehat, serta tekstur yang menarik.

\section{Analisa SWOT}

\section{Strenght (Kekuatan)}

Yang diunggulkan dari produk ini adalah tampilan dan rasa, tampilan memiliki fisik yang menarik dipandang, dan "menggoda" saat dipandang. Membuat orang penasaran dan membuat rasa penasaran itu menjadi keingintahuan. Serta rasa yang beda namun tetap khas bagi bahan tradisional Indonesia. Buah-buahan yang digunakan juga sangat fresh, dan tidak menggunakan perasa buah atau pewarna.

Walaupun tampilannya mengikuti budaya orang barat namun bahan pokok ini dapat diterima oleh orang-orang. Serta harga yang tidak mahal menjadikannya siapapun dapat membelinya. Tidak perlu merogoh kocek dalam-dalam agar dapat menikmati desert ini.

\section{Weakness (Kelemahan)}

Walaupun terlihat menarik dari tampilan serta rasa, ini tidak dapat diterima oleh kalangan tertentu. Seperti orang-orang yang terkena sakit parah, atau orang yang alergi terhadap bahan makanan tertentu seperti susu sapi. Orang tua yang sudah lanjut usia juga tidak dapat mengkonsumsinya jika kesulitan untuk mengelola makanan.

\section{Oportunity (Peluang)}

Banyaknya anak muda yang sangat suka dengan manis alami dari buah-buahan. Sangat menguntungkan bagi produk ini, tempat pembuatan yang dekat dengan tempat penjualan juga sangat menentukan dalam penjualan ini.

\section{Trench (Ancaman)}

Dari lingkungan sekitar ada banyak yang pesaing, ada beberapa toko besar dan ada warung yang terkenal dengan es cream yang sudah banyak orang akui sangat lezat. 


\section{Metode}

Beberapa referensi yang digunakan adalah: proposal kegiatan kreativitas ${ }^{1}$ sebagai contoh proposal. Untuk kajian yang lain untuk mendeskripsikan tulisan proposal ini menggunakan pendekatan kualitatif deskripsi ${ }^{2}$, dan pembuatan laporan atau makalah diberikan contoh karya ilmiah Kewirausahaan Nameko (Nasi merah kotak-kotak). ${ }^{3}$

\section{BAB II}

\section{GAMBARAN UMUM RENCANA USAHA}

\section{GAMBARAN UMUM PRODUK}

Produk yang kami buat ini bernama Ice Cream Fruity, Ice Cream ini berbahan dasar buah yang di sertai dengan toping buah. Ide membuat Ice Cream Fruity ini muncul karena kami merasa banyak masyaraka yang merasa bosan dengan mengonsumsi buah secara langsung, hingga pada akirnya kami memikirkan cara membuat Ice Cream ini dengan menambahkan serat buah didalamnya dan toping berupa buah-buahan.

a. Bahan Pembuatan Produk

- Tepung Han

- Serat Buah Semangka

- Susu

- Gula

- Air mineral

Yang menjadi keunggulan produk ini iyalah, dalam pembuatan kami tidak menggunakan bahan pengawet atau SMG.

b. Komasan

Produk Ice Cream Fruity ini akan dikemas dengan menggunakan cap plastik

\footnotetext{
${ }^{1}$ Jonathan Matheus et al., "Proposal Kegiatan Kreativitas Handmade BOLU (Boneka Lucu)," 2019, https://osf.io/nwdap/.

${ }^{2}$ Hengki Wijaya and Helaluddin Helaluddin, Analisis Data Kualitatif Sebuah Tinjauan Teori \& Praktik (Makassar: Sekolah Tinggi Theologia Jaffray Makassar, 2019).

${ }^{3}$ Hengki Wijaya and Tuflikha P. Putri, "KEWIRAUSAHAAN NAMEKO (NASI MERAH KOTAKKOTAK) DALAM MENGGIATKAN PANGAN LOKAL YANG SEHAT” (Prosiding Seminar Nasional Pangan, Teknologi, dan Entrepreneurship, Makassar, Indonesia: Universitas Fajar Makassar, 2019), https://osf.io/vzd48.
} 


\section{PELUAN PEMASARAN}

Produk ini akan kami pasarkan dilingkungan kampus, yang menjadi target pemasaran adalah mahasiswa/i dan dosen yang ada. Produk ini akan kami jual dengan harga berkisaran Rp. 15.000,- sampai dengan Rp. 20.000,- setiap harga mempengaruhi porsi dari produk ini.

\section{Gambaran strategi pemasaran}

Cara kami memperkenalkan produk ini melalui media sosial dan pembauatan brosur yang kami sebarkan melalui media sosial, selain dari pada itu kami juga menawarkan peroduk kami ini scara langsung kepada orang-orang disekitar kami.

\section{BAB III}

METODE PELAKSANAAN

Uraian teknis cara membuat komoditas usaha

Komposisi bahan terdiri dari :

Bahan Ice Cream :

1. 1 Buah Semangka

2. Susu DanCow 4 sct

3. Tepung Haan 4 bungkus

4. air minum $600 \mathrm{ml}$

5. Toping buah berupa jeruk, anggur dan pisang

Alat produksi terdiri dari :

1. Baskom

2. mixer

3. pisau

4. blender

5. cool box agar tidak cepat lumer

6. sendok pembulat ice cream

Kemasan :

Produk Ice Cream ini menggunakan kemasan cup plastic yang dilengkapi dengan sendok Perlengkapan :

1. mesin pendingin Ice agar Ice Cream tidak lumer

2. Gerobak kios untuk menjangkau orang-orang yang ada di RT/RW secara langsung 
3. sepeda motor untuk menjangkau pembeli yang ada di sekolah-sekolah, yang tempatnya lumayan jauh

\section{Training Tenaga Pemasaran :}

1. Melengkapi para karyawan/karyawati yang akan ditugaskan memasarkan dengan pengetahuan selain Cara memasukkan Ice Cream ke dalam kemasan baik Krupuk atau Cup saat pembeli datang. Dan untuk cara jual ice cream yang sudah dikemas saat di workshop, sehingga memudahkan saat mereka memasarkan, baik yang langsung dipasarkan dengan sasaran pembeli adalah penduduk yang tinggal di daerah tersebut

2. juga ice cream yang sudah dikemas di workshop dengan sasaran kerja sama-sama dengan toko-toko yang diharapkan menjadi agen untuk memasarkan. Bagian pemasaran untuk tokotoko sudah dilengkapi dengan :

a. Harga khusus untuk dealer sehingga toko-toko berkenan menjual karena bagian

keuntungannya dianggap cukup. Dan dalam hal yang lain harga ice cream buatan kami, tetap dapat bersaing dengan perusahaan ice cream lainnya.

b. Mesin pendingin khusus toko-toko agar pelaanggan langsung bisa memilih sendiri, ice cream.

Tahap-tahap yang dilalui untuk pemasaran :

1. Sasaran penjualan langsung ke RT/RW dengan gerobak-gerobak cantik.

2. Penjualan sepeda motor untuk jangkau sekolah-sekolah dan tempat yang agak jauh

3. Mobil-mobil pemasaran untuk menjangkau toko-toko yang menjadi dealer.

- Toko-toko di pasar tradisional.

- Toko-toko yang lokasinya dijalan raya yang ramai.

Taahap-tahap penetapan biaya operasional agar memperoleh untung :

1. Harga bahan-bahan yang dipakai

2. Biaya listrik dan lain-lain

3. Gaji karyawan

4. Bahan bakar untuk sepeda motor dan mobil pengantar

5. Biaya tiba-tiba atau pengeluaran tak terduga.

Seperti mesin pendingin rusak, sepeda motor dan mobil harus service, karyawan sakit dan lainlain.

Semua harus dihitung dengan cermat dalam perhitunganmodal produksisehingga tidak salah dalam menetapkan harga jual. 


\section{BAB IV}

ANGGARAN BIAYA DAN JADWAL KEGIATAN

Biaya yang diperlukan oleh kelompok adalah sebagai berikut :

\begin{tabular}{|c|c|c|}
\hline No & Jenis Pengluaran & Biaya $(\mathbf{R p})$ \\
\hline \multirow[t]{8}{*}{1.} & Peralatan Yang digunakan & \\
\hline & Baskom & Rp. $10.000,00$ \\
\hline & Mixer & Rp. 260.000,00 \\
\hline & Pisau & Rp. 5.000,00 \\
\hline & Blender & Rp. $120.000,00$ \\
\hline & Cool box Lion Star & Rp. 300.000,00 \\
\hline & Sendok Es Cream & Rp. 20.000,00 \\
\hline & Total & Rp. 715.000,00 \\
\hline \multirow[t]{6}{*}{2.} & Bahan Yang digunakan & \\
\hline & 1 Buah Utuh Semangka & Rp. $80.000,00$ \\
\hline & 4 Sct Susu Bubuk $(1=3.500) 4 \times 3.500$ & Rp. $14.000,00$ \\
\hline & Air Minum mineral $600 \mathrm{ml}$ & Rp. $5.000,00$ \\
\hline & Buah berupa Jerus, Anggur, Apel, Pisang 1/2 Kg & Rp. 50.000,00 \\
\hline & Total & Rp. 149.000,00 \\
\hline \multirow[t]{7}{*}{3.} & Alat Untuk Penjualan & \\
\hline & 1 Buku Nota & Rp. 5.000,00 \\
\hline & Gelap Cup Es Cream Besar & Rp. 50.000,00 \\
\hline & Sendok Es Cream & Rp. $10.000,00$ \\
\hline & Plastik dengan Ucapan "Trimakasih" & Rp. $25.000,00$ \\
\hline & Total & Rp. 90.000,00 \\
\hline & Total $1+2+3$ & $\underline{\text { Rp. 954.000,00 }}$ \\
\hline
\end{tabular}


Adapun jadwal kegiatan yang sudah ditetapkan oleh kelompok adalah sebgai berikut:

\begin{tabular}{|l|l|c|c|c|}
\hline \multirow{2}{*}{ No } & \multicolumn{1}{|c|}{ Jenis kegiatan } & \multicolumn{3}{|c|}{ Bulan } \\
\cline { 3 - 5 } & & 1 & 2 & 3 \\
\hline 1 & Belajar Materi Produk & & & \\
\hline 2 & Mendiskusikan Produk dan Mempresentasikan & & & \\
\hline 3 & Training Pembuatan Produk & & & \\
\hline 4 & Tertymonial Produk & & & \\
\hline 5 & Penjualan Produk & & & \\
\hline
\end{tabular}

\section{Daftar Pustaka}

Matheus, Jonathan, Hengki Wijaya, Grace Irene Kalamu, and Josevina Maria Penfani. "Proposal Kegiatan Kreativitas Handmade BOLU (Boneka Lucu)," 2019. https://osf.io/nwdap/.

Wijaya, Hengki, and Helaluddin Helaluddin. Analisis Data Kualitatif Sebuah Tinjauan Teori \& Praktik. Makassar: Sekolah Tinggi Theologia Jaffray Makassar, 2019.

Wijaya, Hengki, and Tuflikha P. Putri. "KEWIRAUSAHAAN NAMEKO (NASI MERAH KOTAK-KOTAK) DALAM MENGGIATKAN PANGAN LOKAL YANG SEHAT." Makassar, Indonesia: Universitas Fajar Makassar, 2019. https://osf.io/vzd48. 